\title{
Current status of acute spinal cord injury pathophysiology and emerging therapies: promise on the horizon
}

\author{
James W. Rowland, B.Sc.H., ${ }^{1}$ Gregory W. J. Hawryluk, M.D., ${ }^{1,2}$ Brian Kwon, M.D., \\ Ph.D., F.R.C.S.C., ${ }^{4}$ ANd Michael G. Fehlings, M.D., Ph.D., F.R.C.S.C., ${ }^{1-3}$ \\ ${ }^{1}$ Division of Genetics and Development, Toronto Western Research Institute, Institute of Medical Science, \\ University of Toronto; ${ }^{2}$ Division of Neurosurgery, University of Toronto; ${ }^{3}$ Spinal Program, \\ University Health Network, Toronto Western Hospital, Toronto; and ${ }^{4}$ Department of Orthopaedics, \\ University of British Columbia, Vancouver, British Columbia, Canada
}

\begin{abstract}
This review summarizes the current understanding of spinal cord injury pathophysiology and discusses important emerging regenerative approaches that have been translated into clinical trials or have a strong potential to do so. The pathophysiology of spinal cord injury involves a primary mechanical injury that directly disrupts axons, blood vessels, and cell membranes. This primary mechanical injury is followed by a secondary injury phase involving vascular dysfunction, edema, ischemia, excitotoxicity, electrolyte shifts, free radical production, inflammation, and delayed apoptotic cell death. Following injury, the mammalian central nervous system fails to adequately regenerate due to intrinsic inhibitory factors expressed on central myelin and the extracellular matrix of the posttraumatic gliotic scar. Regenerative approaches to block inhibitory signals including Nogo and the Rho-Rho-associated kinase pathways have shown promise and are in early stages of clinical evaluation. Cell-based strategies including using neural stem cells to remyelinate spared axons are an attractive emerging approach. (DOI: 10.3171/FOC.2008.25.11.E2)
\end{abstract}

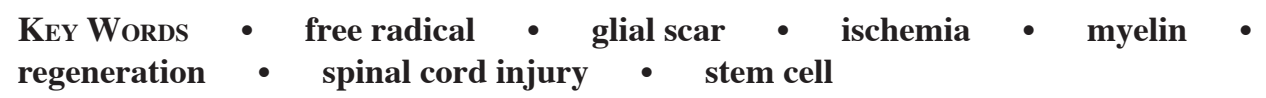

$\mathrm{T}$ HE reversal of paralysis following SCI is among the most daunting challenges in all of neuroscience research. Despite significant improvements in the early medical and surgical management of SCI, coupled with a vastly improved understanding of SCI pathophysiology, there remain no effective treatments to improve neurological outcomes following SCI. Although a num-

\footnotetext{
Abbreviations used in this paper: $\mathrm{BBB}=$ blood-brain barrier; $\mathrm{BMSC}=$ bone marrow stromal cell; $\mathrm{cAMP}=$ cyclic adenosine monophosphate , ChABC = chondroitinase $\mathrm{ABC} ; \mathrm{CNS}=$ central nervous system; $\mathrm{CSPG}=$ chondroitin sulfate proteoglycan; $\mathrm{ESC}=$ embryonic stem cell; FasR $=$ Fas receptor; GAG = glycosaminoglycan; HSC = hematopoietic stem cell; IL = interleukin; $\mathrm{iPSC}=$ induced pluripotent stem cell; MAG = myelin-associated glycoprotein; $\mathrm{MSC}=$ mesenchymal stem cell; $\mathrm{NgR}=$ Nogo-66 receptor; NMDA $=N$-methyl-D-aspartate; $\mathrm{NPC}=$ neural progenitor cell; $\mathrm{NSC}=$ neural stem cell; $\mathrm{OEC}=$ olfactory ensheathing cell; OMgp = oligodendrocyte-myelin glycoprotein; OPC = oligodendrocyte progenitor cell; $\mathrm{PNS}=$ peripheral nervous system; $\mathrm{ROCK}=$ Rho-associated kinase $; \mathrm{ROS}=$ reactive $\mathrm{O}_{2}$ species; $\mathrm{SCI}=$ spinal cord injury; $\mathrm{TNF}=$ tumor necrosis factor.
}

ber of pharmacological agents (such as methylprednisolone sodium succinate and the related compound tirilazad mesylate, GM-1 ganglioside, thyrotropin-releasing hormone, gacyclidine, naloxone, and nimodipine) have been investigated in large, prospective, randomized, controlled clinical trials, all have failed to demonstrate convincing neurological benefit, despite the promise that these agents demonstrated in preclinical animal studies of SCI. The aim of this review is to provide an overview of the current state-of-the-art of SCI pathophysiology while highlighting the important aspects for which therapeutic interventions are being developed. The latter half of the review will discuss recent preclinical advances in SCI therapies, focusing mainly on cell-based approaches, and comment on the potential for clinical translation that exists.

\section{Epidemiology of SCI}

Acute traumatic SCI occurs worldwide with an estimated annual incidence of $15-40$ cases per million ${ }^{146}$ and 
M. G. Fehlings et al.

TABLE 1: Spinal cord injury phases and key pathological events

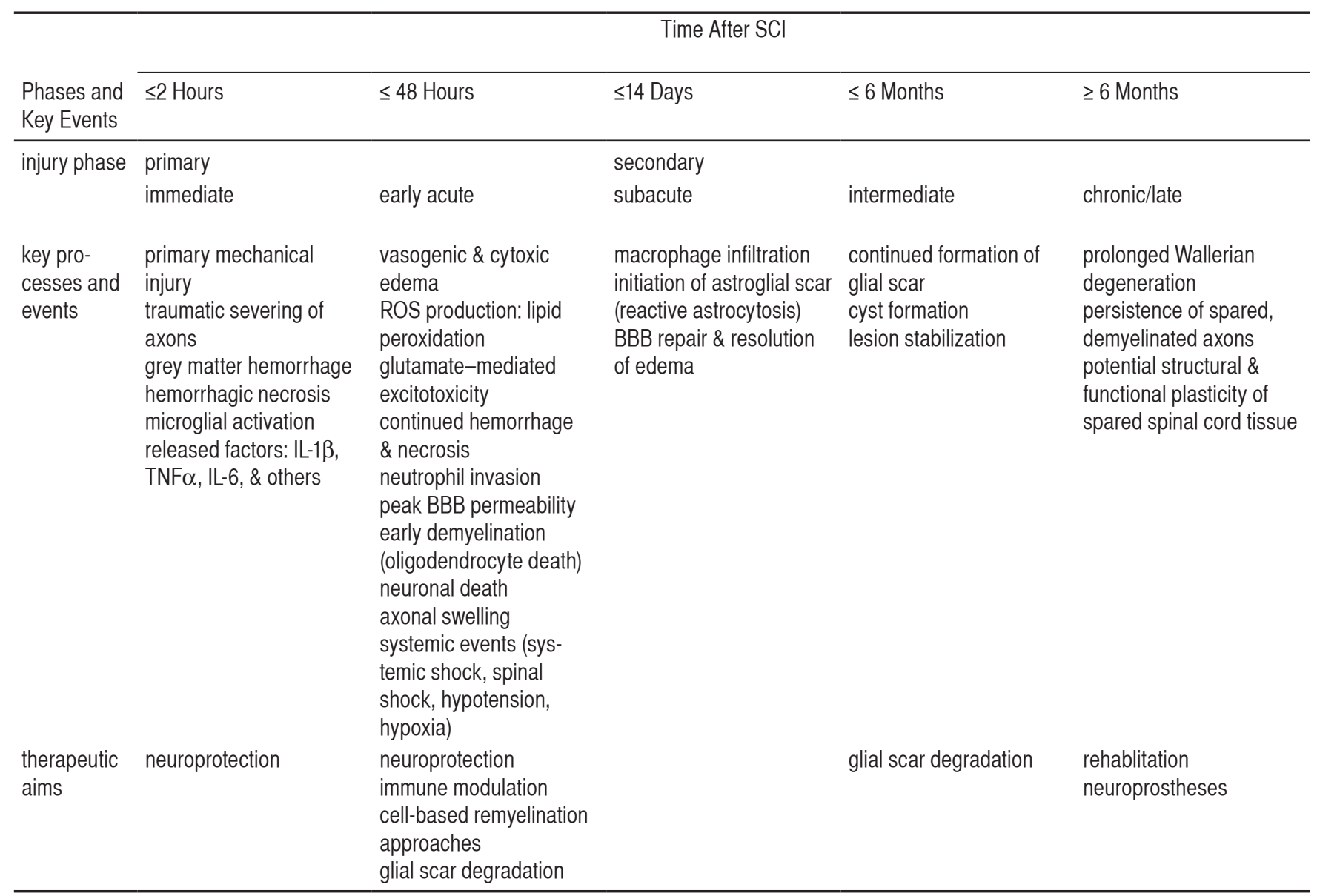

is associated with severe physical, psychological, social, and economic burdens on patients and their families. It has been estimated that the lifetime cost of medical care and other injury-related expenses for a 25 -year-old patient with SCI who suffers a high cervical tetraplegia is US $\$ 3$ million. ${ }^{128}$ At the societal level, SCI is particularly troubling because it predominantly occurs in young, otherwise healthy individuals, with injury occurring with the greatest frequency in those between 15 and 25 years of age. The male-to-female ratio for SCI is $\sim 4$ to $1 .{ }^{103}$ During the previous 3 decades there has been a subtle shift in SCI demographics with the average age at injury increasing from 28.7 to 37.6 years and the percentage of injuries occurring in the elderly (those $>60$ years of age) increasing from 4.7 to $10 \%$ of SCI cases. ${ }^{4,74}$ Common causes of SCI are motor vehicle accidents (50\%), falls and work-related injuries (30\%), violent crime (11\%), and sports-related injuries $(9 \%){ }^{74}$ Flexible regions of the spinal column are most susceptible to injury and accordingly, injuries most commonly occur in the cervical spine where they are associated with the most devastating neurological impairments. A recent report from the US National Spinal Cord Injury Database found that $56 \%$ of all SCI cases occur in the cervical spine. ${ }^{4}$

\section{Pathophysiology of SCI}

A prerequisite to the development of effective therapies for SCI is a detailed understanding of the pathophysiological processes occurring following injury and how various components interact to result in the functional deficits observed. This understanding is complicated by the finding that several elements of the injury responsenotably the inflammatory response and reactive astrogliosis-have been found to act pathologically while also serving some neuroprotective or neurorestorative functions.

The pathophysiology of SCI is best described as biphasic, consisting of a primary and secondary phase of injury (Table 1). The primary phase involves the initial mechanical injury during which failure of the spinal column (fracture and/or dislocation) directly imparts force to the spinal cord, disrupting axons, blood vessels, and cell membranes. This is followed by the delayed onset of a secondary injury phase involving vascular dysfunction, edema, ischemia, excitotoxicity, electrolyte shifts, free radical production, inflammation, and delayed apoptotic cell death. Whereas neurological deficits are present immediately following the initial injury, the secondary injury phase results in a protracted period of tissue destruction. 


\section{Spinal cord injury pathophysiology and regenerative approaches}

Due to the many inherent difficulties associated with studying human postmortem tissue, almost all of our detailed understanding of SCI pathophysiology has been obtained through animal studies. The pathophysiology of SCI has been extensively studied in many experimental animal models including mice, rats, cats, and nonhuman primates. While the overall picture of SCI emerging from each species investigated has been equivocal, some significant differences exist between the human condition and rodent models widely used in preclinical studies, such as the extent of glial scarring. ${ }^{66}$

\section{Primary Injury Phase}

The most common form of acute SCI is a compressive-contusive-type injury in which displaced components of the vertebral column, including intervertebral discs and ligaments, exert force on the cord causing both immediate traumatic injury and often sustained compression. ${ }^{146}$ The common physical mechanisms of primary injury include shearing, laceration, acute stretching, and sudden acceleration-deceleration injuries. ${ }^{9}$ Primary injury mechanisms rarely transect or fully disrupt the anatomical continuity of the cord. Axons are commonly found to traverse the lesion site, often occupying a "subpial rim" of spared yet demyelinated or dysmyelinated long-tract axons. ${ }^{23,101,114,130,156}$ The existence of these spared axons crossing the injury site is highly significant therapeutically and represents the neural substrate on which many emerging therapeutic strategies will act. It is also encouraging, because in animal studies substantial neurological function has been sustained with the preservation of as few as $5 \%$ of the original number of axons. ${ }^{54,79}$ Therefore, approaches (such as remyelination) to enhance the function of residual neural tissue may maximize the potential neurological recovery in a given patient, even in the absence of significant neural or axonal regeneration. Rehabilitative therapy is also essential to maximizing neurological recovery in patients with SCI. ${ }^{48}$ Although beyond the scope of this review, rehabilitative approaches, such as weight-assisted treadmill training or functional electrical stimulation, ${ }^{131}$ are and will continue to be a vital component in future treatment regimes for SCI (for review, see reference 48). One particularly promising area of research in SCI rehabilitation worthy of brief discussion is the development of techniques to stimulate motor neuron pools and networks caudal to the lesion. Pioneering work by Grillner ${ }^{63-65}$ identified neuronal networks intrinsic to the spinal cord, termed "central pattern generators," that mediate locomotor output including walking in vertebrates. Building on this work, Chau and colleagues ${ }^{30}$ have demonstrated that in the cat these "spinal locomotor" central pattern generators can be activated both pharmacologically by clonidine or by sensory input through treadmill training ${ }^{10}$ to result in functional locomotion with full weight support, even after complete transection of the spinal cord. Therefore, rehabilitation programs should be designed to improve both voluntary and involuntary aspects (spinal locomotor central pattern generators) of motor control to maximize functional recovery following SCI.

\section{Secondary Injury Mechanisms}

A number of pathophysiological processes are triggered by the primary mechanical injury leading to the prolonged secondary injury phase. These events of this secondary injury process can be usefully divided temporally into multiple contiguous phases: the immediate, acute, intermediate, and chronic stages of SCI (Table 1).

\section{Immediate Phase (0-2 Hours)}

The immediate phase begins at the time of injury, lasts $\sim 2$ hours, and represents the primary phase of injury in the biphasic SCI model. ${ }^{118}$ This phase is dominated by the immediate results of the injurious event itself. The traumatic severing of axons, the immediate death of neurons and glia, and the accompanying (poorly understood) phenomenon of spinal shock ${ }^{44}$ result in instantaneous loss of function at and below the level of injury for complete injuries.

The first detectable pathological change following injury is a generalized swelling of the spinal cord often with hemorrhaging in the central gray matter, in which cells immediately begin undergoing necrotic death due to direct mechanical disruption of cell membranes or ischemia resulting from vascular disruption. Disruption of the microvasculature also leads to hemorrhage (largely petechial) in the surrounding white matter. ${ }^{79,151}$ Hemorrhage and swelling combine to produce cord ischemia that may extend for many spinal segments both rostral and caudal to the injury. Interestingly, gross morphological or MR imaging abnormalities of the spinal cord can be absent during the immediate phase with the exception of patients suffering from severe compressive or lacerative injuries. ${ }^{6,118}$

Although profound histopathological changes may not yet be grossly observable in this early injury phase, other injurious pathophysiological processes have been initiated. For example, the activation of microglial cells begins almost instantaneously following injury ${ }^{46}$ with the upregulation of the proinflammatory cytokines TNF $\alpha$ and IL- $\beta$, detectable within minutes of injury. ${ }^{125}$ Levels of extracellular glutamate can reach excitotoxic levels within minutes of the injury. ${ }^{163}$

\section{Acute Phase}

The acute phase is the period in which the secondary injury processes become dominant. For practical reasons, it is the SCI phase likely to be most amenable to neuroprotective interventions, as it is typically the earliest point at which patients arrive at an appropriate center to receive possible treatment. The acute phase is subdivided into early acute and subacute stages.

Early Acute Phase (2-48 Hours). The early acute phase of SCI can be considered to last from 2 to 48 hours following injury. This phase is characterized by continuing hemorrhage, increasing edema, and inflammation, and marks the onset of additional secondary injury processes including free radical production, ionic dysregulation, glutamate-mediated excitotoxicity, and immuneassociated neurotoxicity that contribute to further axonal injury and cell death. Vascular disruption, hemorrhage, 
and the resulting ischemia are central constituents of this secondary injury cascade. ${ }^{150,151}$ The vascular mechanisms underlying the prolonged ischemia are not fully understood, although major spinal arteries are typically intact following injury. The disruption of the microvasculature, loss of normal autoregulatory mechanisms, global hypotension, and increased interstitial pressure underlie the prolonged hypoperfusion seen after SCI. ${ }^{87,150,151}$ The ischemia results in cytotoxic cell swelling that affects both neurons and glia. Axonal swelling is common, leading to action potential blockade. ${ }^{79}$ The following sections describe elements of the secondary injury cascade prominent during the early acute phase of injury and important potential therapeutic targets.

Ionic Dysregulation and Excitotoxicity. The loss of ionic homeostasis immediately following SCI and excitotoxicity are closely related processes that each significantly contribute to the propagation of cellular injury after SCI. The loss of appropriate ionic homeostasis is a central feature of both necrotic and apoptotic cell death following injury. Specifically, the dysregulation of $\mathrm{Ca}^{++}$ ion concentration is a common element in cell death ${ }^{140}$ and initiates a number of damaging processes including the activation of calpains, mitochondrial dysfunction, and free radical production culminating in cell death.

Excitotoxicity is a result of the excessive activation of glutamate receptors leading to the influx of $\mathrm{Na}^{+}$and $\mathrm{Ca}^{++}$through the NMDA and alpha-amino-3-hydroxy-5methyl-isoxazoleproprionate/kainate receptors. It is believed to play a role in the death of both neurons and glia following many forms of neurotrauma, including SCI (for review, see reference 119). Following injury, extracellular levels of glutamate rise rapidly due to direct injury to cells and failure of energy-dependent transporters, notably the $\mathrm{Na}^{+} \mathrm{K}^{+}$adenosine triphosphatase membrane transporter that normally functions to regulate extracellular concentrations of ions, glutamate, and other molecules. ${ }^{91}$ The prominent role of excitotoxicity in the propagation of secondary injury has led to significant interest in pharmacological means to attenuate it with antagonists of NMDA and non-NMDA receptors.

Free Radical Mediated Injury. Free radical mediated injury is an important contributor to secondary damage following SCI with radical-mediated lipid peroxidation contributing to axonal disruption and the death of both neurons and glia. Lipid peroxidation is a self-perpetuating free radical reaction causing membrane damage leading to cell lysis, the dysfunction of organelles, and contributing to calcium dyshomeostasis through the oxidation of membrane lipids. The detection of ROS peaks at roughly 12 hours following injury and remains elevated for $\sim 1$ week, returning to basal, preinjury levels 4-5 weeks after injury. ${ }^{46,164}$ The production of ROS is associated with both ischemia immediately following injury and subsequent reperfusion. ${ }^{139}$ Whereas a variety of radical species contribute to damage, with classic examples such as hydrogen peroxide and the hydroxyl radical, it has recently been shown that a key mediator of ROS-mediated injury is the peroxynitrite radical generated by the reaction of nitric oxide and the superoxide radical. ${ }^{164}$ Peroxynitrite has been directly associated with the induction of apopto- sis in neurons in rat SCI. ${ }^{8}$ Highlighting the importance of ROS in SCI pathology is the demonstrated neuroprotective effects of antioxidant compounds such as tempol ${ }^{73}$ and selective inhibition of peroxynitrite-mediated reactions by uric acid. ${ }^{144}$ The modest neuroprotective effects of the now standard methylprednisolone treatment following SCI are also believed to be due, at least in part, to the inhibition of lipid peroxidation. ${ }^{53,87}$ Therefore antioxidant therapy is an important area of continuing investigation for neuroprotective compounds for SCI.

Permeability of the BBB. In the uninjured CNS the BBB functions as a highly selective filter limiting the transport of compounds both into and out of the CNS parenchyma. Following SCI there is a marked increase in $\mathrm{BBB}$ permeability due to both direct mechanical disruption by the primary injury and the effects on endothelial cells by numerous inflammatory mediators and other compounds that are upregulated after SCI. The time course of changes in BBB permeability following experimental SCI can be accurately assessed using the extravasation of horseradish peroxidase as an indicator of microvasculature permeability in the spinal cord. Following contusive SCI in the rat, it has been shown that peak $\mathrm{BBB}$ permeability occurs at 24 hours following injury, returning to control levels by 2 weeks. ${ }^{117}$ The time course of $\mathrm{BBB}$ permeability change has not been established in human SCI, although it may be speculated to be similar. Whereas the initial rise in permeability is largely due to direct mechanical disruption of the endothelial cells and astrocytic processes forming the BBB (almost an immediate phenomenon after injury), a number of inflammatory mediators involved in the secondary injury cascade are known to have profound effects on vascular permeability. Two inflammatory cytokines (TNF $\alpha$ and IL-1 $\beta$ ) are upregulated following SCI $^{125}$ and are known to increase vascular permeability. ${ }^{141}$ Other compounds released by glial cells or invading immune cells believed to play a role in increasing BBB permeability include ROS, nitric oxide, histamine, matrix metalloproteinases, and elastase. ${ }^{46}$ Because some hydrophilic agents may not be able to cross the BBB and gain access to the injured spinal cord, methods for manipulating the BBB permeability may have some therapeutic utility. ${ }^{46}$ For many neuroprotective agents administered at early time points when the $\mathrm{BBB}$ remains disrupted, the issue of $\mathrm{BBB}$ permeability may not pose a major problem.

Inflammatory Mediators and the Cellular Immune Response. The early acute stage involves infiltration by inflammatory cells and continuing activation of resident microglia. The inflammatory process following SCI is highly complex and involves numerous cellular populations, including astrocytes, microglia, T cells, neutrophils, and invading monocytes. A multitude of noncellular mediators, including TNFo, interferons, and ILs also play important roles. ${ }^{46,56,127}$ The field of neuroinflammation following SCI has grown immensely in recent years and has revealed a process of tremendous complexity, with some aspects of the inflammatory response contributing deleteriously to further secondary injury, and others contributing beneficially to the removal of cellular debris and enhancement of the environment for regenerative growth. ${ }^{56}$ 


\section{Spinal cord injury pathophysiology and regenerative approaches}

The dual nature of the immune response following SCI is well demonstrated by the multiple roles observed for TNF $\alpha$ following CNS injury. Tumor necrosis factor- $\alpha$ is key inflammatory media that is significantly upregulated in neurons, glia, and endothelial cells following SCI. ${ }^{166}$ The inhibition of TNF $\alpha$ signaling using neutralizing antibodies has been demonstrated to improve functional neurological recovery following SCI. ${ }^{15}$ However, TNF $\alpha$ signaling has also been demonstrated ${ }^{15}$ to have a neuroprotective role both in vitro $^{32}$ and following SCI in TNFo-deficient mice who display higher numbers of apoptotic cells, increased lesion size, and worsened functional recovery when compared with wild-type mice. ${ }^{84}$ These conflicting effects highlight the need for further characterization of the inflammatory response and a clear delineation of the deleterious and beneficial aspects to target therapeutically. The study of the diverse components of the immune response in human SCI is complicated by the difficulty in obtaining pathological samples at early time points after injury, a task that was recently achieved by Fleming and colleagues ${ }^{56}$ in their elegant description of the cellular response to human SCI.

Cell Death and Demyelination. Cell death after SCI may occur by necrosis or apoptosis. Death of neurons at all stages of injury occurs mainly through necrosis, ${ }^{13}$ with little evidence to date that apoptosis plays an important role in neuronal death after human $\mathrm{SCI}^{51,81}$ although it has been observed in animal SCI. ${ }^{94,169}$ In contrast to this, oligodendrocytes - which, like neurons, are highly sensitive to ischemic injury-readily undergo apoptosis following SCI. ${ }^{38}$ This process is at least partly dependent on the activation of oligodendrocyte Fas receptors by activated microglia expressing Fas ligand ${ }^{27,28}$ and signaling through the p75 neurotrophin receptor. ${ }^{12,36}$

Because apoptotic death is an active process, as it is both energy dependent and requiring de novo protein synthesis, it represents a feasible target for therapeutic intervention by selective inhibition. ${ }^{19}$ Recent work in our laboratory has demonstrated the potential efficacy of interfering with Fas-mediated apoptosis. Following SCI, Fas ligand is expressed by microglia and invading lymphocytes while the FasR is predominantly found on oligodendrocytes. ${ }^{27,28,112}$ The interaction of Fas and FasR initiates apoptosis through the activation of the caspase cascade leading to proteolysis and DNA cleavage by effector caspases culminating in cell death (for review, see reference 112). The potential for blocking Fas-mediated cell death following SCI using a soluble form of the FasR has been demonstrated using an in vitro system ${ }^{7}$ and through the intrathecal administration of a soluble form of the FasR to competitively inhibit endogenous Fas signaling following SCI in rats. ${ }^{1}$ Oligodendrocytes are also susceptible to excitotoxic cell death following injury due to their recently discovered expression of NMDA receptors. ${ }^{148}$ The loss of oligodendrocytes results in axonal demyelination, which peaks at $\sim 24$ hours following injury in the rat. ${ }^{156}$ Persistent demyelination and other forms of axonal injury (such as traumatic disruption, lipid peroxidation, and ischemic swelling) are associated with the atrophy and potential death of the associated cell bodies. ${ }^{118,129,173}$ Animal studies have provided strong evidence that spared demyelinated axons are present following contusive SCI, and represent an important therapeutic target for SCI treatments that either remyelinate (cell transplants) ${ }^{157}$ or improve axonal conduction in demyelinated fibers (4-aminopyridine).$^{70,114,115}$ On the other hand, postmortem human studies and a limited number of animal studies ${ }^{88}$ have not convincingly demonstrated that spared demyelinated axons are present to a significant extent after human SCI. Interestingly, in both Kakulas' ${ }^{79}$ and Norenberg et al.'s ${ }^{118}$ large, independent descriptions of the chronic pathology of human SCI, both authors observed little to no demyelinated axons, and commented on how this differed from the animal setting. The failure to observe demyelinated axons may be attributable to technical issues, and Guest et al. ${ }^{172}$ subsequently described finding "some unmyelinated axonal profiles" in 4 of 7 postmortem SCI cases with the use of double-labeling fluorescent techniques. This finding, of course, has important implications on the relevance of cell transplantation strategies to promote remyelination as a therapeutic strategy and arguably represents one of the most important unanswered questions in SCI pathology. Emerging MR imaging technologies including magnetization transfer ${ }^{55}$ and diffusion tensor imaging ${ }^{96}$ are important tools in improving our understanding of the role of demyelination and remyelination following human SCI and will play a key role in corroborating structural repair with functional improvements in future clinical trials.

Subacute Phase (2 Days to 2 Weeks). The subacute phase is considered to last from $\sim 2$ days to 2 weeks following injury and importantly is the time period in which future cell-based therapeutic strategies are most likely to be applied. For example, recent work in our laboratory has shown that transplantations of adult neural precursor cells at 2 weeks after SCI in rats promotes remyelination and functional recovery, whereas cells transplanted at later, chronic time points fail to adequately survive, migrate, and differentiate to promote functional recovery. ${ }^{80}$ This failure of transplanted cells to survive when transplanted either immediately at the time of injury or after the subacute phase has also been observed by Keirstead and coworkers ${ }^{82}$ using human ESC-derived oligodendrocyte progenitors.

The phagocytic response is maximal during the subacute period and is likely beneficial in removing cell debris from the lesion area and may promote axon growth to some degree through the removal of growth-inhibitory components of myelin debris. ${ }^{46}$ The phagocytic response observed following PNS injury is significantly greater than that of the CNS and may account for some degree of the difference in regenerative ability.

Following SCI, astrocytes in the lesion core display cytotoxic edema and undergo necrotic cell death in the hours to days following injury. A somewhat delayed astrocytic response begins in the subacute phase, in which astrocytes at the periphery of the lesion become hypertrophic and proliferative, correlating with a dramatic increase in the expression of the astrocytic intermediate filament glial fibrillary acidic protein. These reactive astrocytes grow multiple, large cytoplasmic processes that interweave to form the astrocytic (gliotic) scar. This scar represents both a physical and chemical barrier (see be- 
TABLE 2: Summary of SCl therapies under development and proposed mechanism of actions underlying functional recovery

\begin{tabular}{|c|c|c|}
\hline Approach & Effect & Mechanism of Action \\
\hline \multicolumn{3}{|l|}{ molecular approaches } \\
\hline soluble Fas receptor & reduced apoptosis & competitive inhibition of FasL-FasR signaling \\
\hline IN-1 (anti-Nogo antibodies) & enhanced regenerative growth of axons & $\begin{array}{l}\text { inhibition of myelin-associated inhibitors } \\
\text { signaling through } \mathrm{NgR}\end{array}$ \\
\hline C3-transferase (Cethrin) & $\begin{array}{l}\text { enhanced regenerative growth of axons } \\
\text { reduced apoptosis }\end{array}$ & inhibition of Rho-ROCK signaling \\
\hline ChABC & reduced glial scarring & enzymatic degradation of CSPG side chains \\
\hline \multicolumn{3}{|l|}{ cellular approaches } \\
\hline Schwann cells & $\begin{array}{l}\text { remyelination } \\
\text { neuroprotection? }\end{array}$ & remyelination (peripheral myelin) \\
\hline OECs & $\begin{array}{l}\text { support of regenerative axon growth, neuro- } \\
\text { protection }\end{array}$ & $\begin{array}{l}\text { integration through astroglial scar production } \\
\text { of neurotrophic factors? }\end{array}$ \\
\hline NSCs, NPCs, and OPCs & $\begin{array}{l}\text { remyelination } \\
\text { support of regenerative axon growth neuro- } \\
\text { protection? }\end{array}$ & $\begin{array}{l}\text { oligodendrocyte differentiation/remyelination } \\
\text { production of neurotrophic factors? }\end{array}$ \\
\hline BMSCs and HSCs & $\begin{array}{l}\text { remyelination? } \\
\text { support of regenerative axon growth? neuro- } \\
\text { protection? } \\
\text { unknown }\end{array}$ & $\begin{array}{l}\text { transdifferentiation? } \\
\text { unknown? }\end{array}$ \\
\hline
\end{tabular}

low) to axonal regeneration. Although prominent following rodent SCI, the extent of astroglial scarring is markedly decreased in humans. ${ }^{66}$ The reason for this difference is unclear and the consequence on the clinical relevance of various treatment strategies to reduce astrocytic scarring in rodent models is an important question that must be addressed. Despite the production of the scar, astrocytes also serve beneficial functions following SCI such as promoting the reestablishment of ionic homeostasis and reestablishing the integrity of the $\mathrm{BBB}$, which is important for the resolution of the edema and in limiting the infiltration of immune cells. ${ }^{71}$

\section{Intermediate Phase (2 Weeks to 6 Months)}

The intermediate phase is characterized by the continued maturation of the astrocytic scar and by regenerative axonal sprouting. ${ }^{72}$ In rat models of contusive SCI, corticospinal tract axons display sprouting from 3 weeks to 3 months following injury, whereas sprouting reticulospinal fibers are observed to sprout from 3 to 8 months postinjury. ${ }^{72}$ Although these regenerative attempts are obviously insufficient in producing significant functional recovery in severe SCI, it is nonetheless encouraging evidence that regenerative potential does exist in the adult spinal cord. The differential responses of various tracts to injury is a particularly interesting observation and the elucidation of the mechanisms behind this phenomenon is of great interest, as it may reveal that different strategies are needed for different neuronal populations.

\section{Chronic Phase (> 6 Months)}

The chronic phase begins $\sim 6$ months following injury and continues throughout the lifetime of the patient with SCI. The chronic phase is characterized by the maturation/stabilization of the lesion including continued scar formation and the development of cysts and/or syrinxes. The process of Wallerian degeneration of injured or severed axons is ongoing and it may take years for severed axons and their cell bodies to be fully removed. ${ }^{13,37,50} \mathrm{De}-$ spite some instances of improved neurological function many years following injury, ${ }^{100}$ it can be considered that at 1-2 years postinjury, the neurological deficits have stabilized and the lesion has fully matured. The lesion itself is characterized by cystic cavitation and myelomalacia, representing the final stage of necrotic death after SCI.

The lesion, unfortunately, may not remain static, and syrinx formation in as many as $30 \%$ of patients with SCI can cause delayed neurological dysfunction (ascending paralysis, brainstem symptoms) and neuropathic pain. ${ }^{147}$ At this chronic stage, therapeutic strategies are aimed to encourage regeneration/sprouting of disrupted axons, promote plasticity with rehabilitation strategies, and improve the function of demyelinated axons with pharmacological measures or cellular transplantation substrates that may potentially remyelinate. Despite much success with stem cell-based approaches when applied subacutely, the successful application of stem cells during this chronic injury phase of injury has not been demonstrated.

As detailed in the preceding sections, SCI pathophysiology involves many mechanistically distinct processes that interact in poorly understood ways to both limit and enhance recovery following injury. This dichotomy is well demonstrated by the astrocytic response, which serves to reestablish the BBB, restore ionic homeostasis, and limit the infiltration by cytotoxic immune cells while 


\section{Spinal cord injury pathophysiology and regenerative approaches}

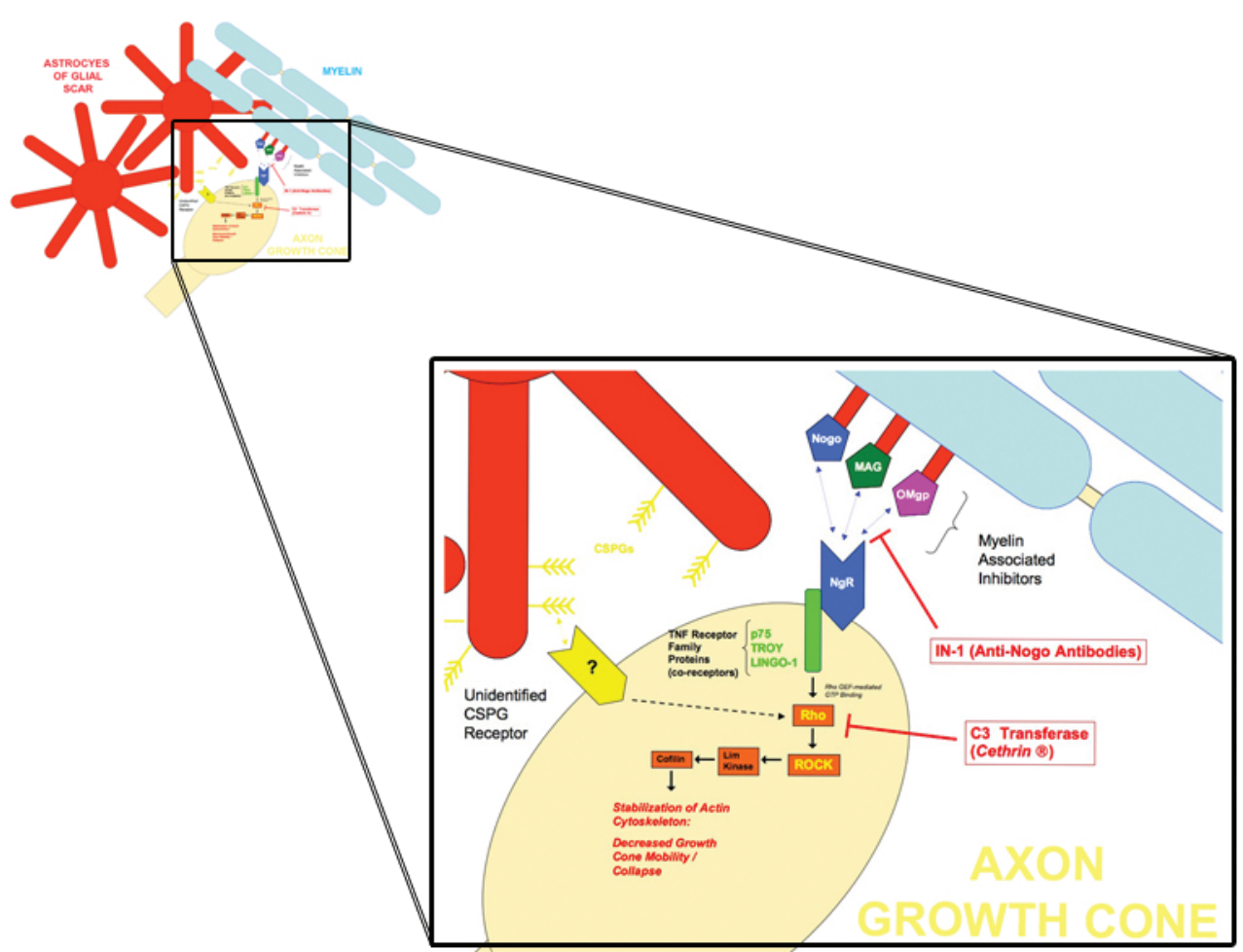

FIG. 1. Schematic illustration of glial inhibitors of axonal growth after SCI. All known myelin inhibitors appear to activate the guanosine triphosphatase Rho, which leads to growth cone collapse. Signaling via NgR has been established for the Nogo, MAG, and OMgp. Other known inhibitors, such as CSPGs, also signal using Rho, but the upstream elements of the pathways have not yet been elucidated (dashed line). Several aspects of this pathway have been targeted in experimental therapeutic strategies. The monoclonal antibody IN-1 inactivates Nogo. Numerous variations of the Clostridium botulinum $\mathrm{C} 3$ transferase protein have been designed, including BA-210 (used in Cethrin), which inactivates Rho by adenosine diphosphate ribosylating its active site.

also severely limiting the ability of axons to regenerate and diminishing functional recovery through the formation of the astrocytic scar. An important consideration for understanding the pathophysiology of human SCI is that each injury is unique in cause and the resultant damage. The contrast between the homogeneity of rodent experimental SCI models and the highly heterogenous human SCI population adds to the challenge of successfully translating treatments to the clinic.

\section{Emerging Regeneration and Repair Strategies}

The next half of this review will focus on novel therapies under development to induce axonal regeneration or sprouting, and cellular-based strategies to promote remyelination of spared axons (Table 2). The failure of axonal regeneration within the CNS is the result of both the growth inhibitory nature of the mammalian CNS and a relatively low intrinsic regenerative competence of CNS neurons. The ability of CNS neurons to regenerate over long distances after axotomy was first established through the pioneering work of Richardson and colleagues in the 1980 s, ${ }^{137}$ in which injured CNS axons were found to regenerate into and through growth-permissive peripheral nerve grafts. The obvious therapeutic potential of these findings for SCI were substantiated with Cheng and asso- ciates' seminal (albeit difficult to reproduce) demonstration in $1996^{33}$ that such peripheral nerve transplantation into a rat spinal cord transection model could promote hindlimb recovery. Incredible optimism followed that such "bridging" strategies would prove helpful for patients with SCIs, although this approach has been largely replaced by cell-transplantation strategies.

In recognition that there are 2 distinct aspects to regenerative failure after CNS injury-the limited intrinsic regenerative potential and the inhibitory extrinsic environment of the injured CNS - great efforts have been undertaken to characterize both. On the intrinsic side, the focus of investigators has been to identify and characterize the molecular signals required to stimulate axonal growth following injury, signals that are clearly more strongly expressed and successfully acted upon in the PNS. Several regeneration-associated genes have been found to be upregulated after axonal injury, notably $L 1, c$-fos, and $c$ jun, and the $43 \mathrm{kD}$ growth-associated protein. ${ }^{29,78}$ Despite these responses, the degree and extent of their expression is apparently insufficient to promote a strong regenerative response in the CNS in contrast to that observed for axotomized PNS neurons. One factor implicated in limiting the regenerative response in CNS axons is a decrease in the levels of intracellular cAMP in mature versus developing neurons. ${ }^{25}$ The elevation of intracellular cAMP lev- 
els using cAMP analogs or the phosphodiesterase inhibitor rolipram has been shown to increase axonal sprouting and reduce the effects of myelin-associated inhibitors (for review, see reference 68 ).

On the extrinsic side, it is well accepted that multiple inhibitory molecules exist that make the injured CNS a nonpermissive environment for axonal growth. These molecules are divided into inhibitors associated with CNS myelin and inhibitors associated with the astrocytic glial scar (Fig. 1).

\section{Myelin-Associated Inhibitors}

The growth inhibitory nature of CNS myelin was first demonstrated in vitro by Schwab and Thoenen ${ }^{143}$ through their observation that cultured sympathetic ganglion neurons would extend neurites on PNS myelin but not CNS myelin. Based on this proof-of-principal experiment, subsequent investigators have identified multiple components of CNS myelin that inhibit axonal growth including Nogo, ${ }^{31}$ MAG, ${ }^{105,111}$ OMgp, ${ }^{159}$ semaphorin 4D, ${ }^{109}$ ephrin B3, ${ }^{14}$ repulsive guidance molecule, ${ }^{69}$ and Netrin- $1 .{ }^{95}$ The identification by Fournier and coworkers ${ }^{58}$ of the receptor for Nogo was followed by the discovery that in addition to Nogo, other myelin-associated inhibitors (MAG and OMgp) also functioned through the $\mathrm{NgR}$, making the receptor an important convergence point for multiple inhibitory signals. The NgR lacks an intracellular signaling domain and transduces inhibitory signals by forming coreceptor complexes with TNF receptor family proteins such as p75, ${ }^{162}$ TROY, ${ }^{121}$ or LINGO- $1 .{ }^{107}$ The identification of the downstream signaling pathways activated by $\mathrm{NgR}$ has been an area of intensive study, with RhoA and the effector kinase ROCK identified as important intracellular mediators. ${ }^{106}$ These in turn regulate further downstream effectors such as Lim kinase and cofilin that function to modify the actin cytoskeleton, leading to the collapse of growth cones on regenerating axons.

A therapeutic approach that has emerged from research into myelin inhibitors is the use of anti-Nogo antibodies. This work was initiated over 2 decades ago with the development of the IN-1 monoclonal antibody, directed against what was then known as 2 neurite outgrowth inhibitors, NI-250 and NI-35, ${ }^{26}$ that were subsequently identified as Nogo. The administration of the IN-1 antibody in a partial transection model of SCI in the rat was found to promote axonal regeneration following injury ${ }^{142}$ and was later demonstrated to promote functional recovery. ${ }^{20}$ Martin Schwab and colleagues ${ }^{31}$ have been dedicated to the development of this antibody approach, which, after the cloning of Nogo as the antigen for IN-1 in 2000, has led to the generation of anti-Nogo antibodies as a directed therapy to neutralize this myelin inhibitor. This approach garnered much interest for rapid clinical translation after reports that a Nogo-A specific neutralizing antibody was found to promote sprouting and improved functional recovery of manual dexterity after cervical SCI in primates. ${ }^{59,60}$ The anti-Nogo antibody treatment strategy has been commercialized by Novartis, and is now undergoing early human evaluation in Europe and Canada (see Hawryluk et al. in this issue) and represents one of the most promising current approaches to enhance axonal regeneration following SCI.
One outstanding question regarding the use of antiNogo treatments (or other myelin inhibitors) is the functionality of the axonal sprouting that might be induced. Myelin-associated inhibitors likely evolved as a means to maintain the structural integrity of synaptic networks formed during development and limit sprouting following developmental pruning and myelination. Whereas anti-Nogo and related strategies promote and enhance regenerative growth, they can also stimulate the aberrant sprouting of uninjured axons ${ }^{22}$ or the inappropriate growth of regenerating axons. Whether this overall increase in plasticity is beneficial remains to be seen, although there is a possibility that it could lead to the development (or exacerbation) of neurological symptoms such as autonomic dysreflexia or neuropathic pain.

\section{Targeting the Rho-ROCK Pathway}

As mentioned above, the discovery of $\mathrm{NgR}$ was rapidly followed by the surprising finding that it was the target for not just Nogo but also for MAG and OMgp. Given that the Rho-ROCK signaling pathway is an important downstream mediator of the Nogo receptor, it represents an important point of convergence for multiple inhibitory signals and a potentially efficient therapeutic target that could block the inhibitory effects of multiple distinct myelin-associated inhibitory molecules. Lisa McKerracher and colleagues ${ }^{90}$ have developed this concept and used the C3 enzyme from Clostridium botulinum (which selectively inactives Rho via adenosine diphosphate ribosylation, without affecting the associated guanosine triphosphatases Rac or Cdc42) to demonstrate that Rho inactivation could enhance CNS regeneration in an optic nerve injury model. It was later demonstrated that Rho-ROCK inhibition promoted axonal sprouting and improved locomotor function in an incomplete thoracic transection model of SCI in the mouse. ${ }^{42}$ Interestingly, the behavioral recovery observed in these animals was very rapid (within days), which was highly suggestive that it could not be mediated by axonal regeneration or sprouting alone. Further study identified a role for activated Rho in apoptotic cell death after SCI and the inhibition of Rho by C3 was found to significantly inhibit this key aspect of secondary injury. ${ }^{47}$ These 2 distinct activities of C3-mediated inhibition of Rho were the impetus to commercialize a C3-like enzyme with improved permeability characteristics under the trade name Cethrin (Alseres Pharmaceuticals, Inc.). This approach has been evaluated in a Phase I/IIa open-label human clinical study and has shown preliminary promise (see article by Hawryluk et al. in this issue).

\section{Glial Scar-Associated Inhibitors}

The glial scar is the result of reactive astrocytosis and is a trademark response to CNS injury of all kinds. The astrocytes that comprise the scar secrete a number of growth inhibitory extracellular matrix components known as CSPGs. ${ }^{104}$ The CSPGs include the molecules neurocan, versican, aggecan, brevican, phosphacan, and NG2. Structurally CSPGs consist of a core protein to which sulfated GAG side chains are covalently linked. ${ }^{110}$ 


\section{Spinal cord injury pathophysiology and regenerative approaches}

Although the GAG side chains are considered the main source of inhibition by CSPGs, it has been postulated that the protein core also contributes to the inhibition of axonal regeneration by acting as a physical barrier to axon elongation, due to high affinity interactions with other extracellular matrix components such as laminin, fibronectin, and neural cell adhesion molecules. ${ }^{168}$

The furthest developed strategy for overcoming this glial barrier is by direct degradation of the CSPGs with a bacterial enzyme known as ChABC that cleaves the GAG side chains from the CSPG core. This approach has been evaluated in numerous in vivo animal models of SCI, although rather infrequently in the most clinically relevant contusion models in which axonal regeneration and sprouting are much more difficult to anatomically assess than in the simpler transection models. Nonetheless, numerous investigators have reported increased sprouting and improved behavioral recovery after ChABC treatment. ${ }^{11,19,24,61,167}$ The possibility of making the CNS environment more permissive to axonal growth has encouraged numerous investigators to use ChABC in combination with other therapies such as fetal tissue transplant, ${ }^{83}$ peripheral nerve transplant, ${ }^{76}$ neural precursor cells, ${ }^{77}$ and Schwann cells ${ }^{57}$ to potentially maximize the capacity for remodeling and plasticity. In the chronic injury setting, the addition of $\mathrm{ChABC}$ to a cellular transplant may indeed be required to address the well-established glial scar.

Interestingly, in another example of convergence between multiple distinct signaling molecules, the inhibitory interactions between axons and CSPGs may also be in part mediated by the Rho-ROCK pathway, ${ }^{108}$ creating the potential that targeting Rho-ROCK and its downstream mediators could also have beneficial effects in helping regenerating axons overcome the glial scar.

\section{Cell-Based Regenerative Strategies}

A surprisingly diverse range of cell types are currently under investigation as potential treatment strategies for SCI and there is considerable variability in the strength of the scientific rationale for various cell types. Overall the therapeutic premise behind the use of cellbased approaches is based on 2 central concepts: 1) to directly replace cells lost due to injury (oligodendrocytes or neurons); and 2) to influence the environment in such a way as to either enhance or support axonal regeneration, provide neuroprotection, or both. Neurons and oligodendrocytes represent the cell types that are lost due to necrotic and apoptotic death after injury, and various cell substrates (such as stem cells, progenitor cells, and Schwann cells) offer the potential of replacing these lost cell populations within the injured cord. The potential of these cells to remyelinate demyelinated axons around the injury site has in particular sparked great interest and has shown the most promise to date. Additionally, such cell substrates may express a number of supportive growth cues, such as neurotrophic factors. ${ }^{93,97}$

Although tremendous optimism abounds regarding the therapeutic potential of cellular substrates for SCI (stem cells in particular), it is important to maintain a realistic perspective on the basic requirements for success and the challenges associated with translation into clinical practice. Stem cells provide a good starting point, as the ability of these cells to differentiate into neurons, oligodendrocytes, or astrocytes in vitro has captured the imagination of basic scientists, clinicians, and patients alike. However, for any cellular substrate to succeed therapeutically, it must meet a number of challenges. A successful cell type must survive following the transplant, differentiate (if not already differentiated) down the correct cell lineage, successfully integrate into the cord tissue, migrate appropriately, physiologically behave in the manner intended, and must be produced in such a way to abide by the Good Manufacturing Process guidelines required for any therapeutic product. One specific area of concern is the potential for contamination of cells with animal antigens such as cell-surface glycoproteins or with viruses. These concerns are now being addressed by the establishment of fully chemically defined culture conditions free of any nonhuman reagents such as fetal bovine serum. Considering that the ideal conditions for cell survival, differentiation, and function that can be generated in vitro will be difficult (if not impossible) to duplicate in vivo within the injured spinal cord, there is good reason for the optimism surrounding cell transplantation to be tempered by the realization of the many obstacles that must be overcome prior to the successful translation of cell-based strategies for SCI. Additionally, many questions remain unresolved regarding the application of this technology, including - on a cell-specific basis-the definition of the optimal time postinjury to perform such a transplant, the patient population most appropriate for the therapy, the techniques required for implanting the cells, and the methods for tracking the fate of the cells in vivo after transplantation.

Given this perspective, the most near-term therapeutic aim for any cell-based therapy is to promote improved axonal function by remyelinating injured demyelinated axons. The following sections will review the cell types that have shown the greatest promise in this regard. It is recognized that in addition to remyelinating denuded axons, these cells may also yield other, still poorly defined growth-promoting effects such as the secretion of neurotrophins or other growth factors.

\section{Cell-Based Remyelination Strategies}

The transplantation of glial cells (oligodendrocytes, Schwann cells, and OECs) or their progenitors from a number of distinct sources has shown great potential for remyelinating demyelinated axons and improving recovery in animal models of SCI. In the setting of cell transplantation studies, remyelinated axons are distinguished from natively myelinated axons by unique structural characteristics including a reduced myelin thickness, shortened internode length, and loss of the linear relationship in the "myelin ratio" between axonal diameter and myelin sheath thickness. ${ }^{101}$ Whereas these differences are useful experimentally to quantify remyelination, ${ }^{80,156}$ it is unclear whether this morphologically abnormal myelin is on its way to being fully remyelinated or, if not, if function will be completely restored. This latter question of 


\section{Spinal cord injury pathophysiology and regenerative approaches}

whether these remyelinated axons are truly functional is rather fundamental (and as yet unanswered) in the field, and is unfortunately difficult to address in in vivo animal studies. The following sections describe the cellular substrates that have been used in SCI research for their ability to remyelinate.

\section{Schwann Cells}

Schwann cells are the myelinating glia of the PNS. The seminal work of David and Aguayo ${ }^{40,41}$ using peripheral nerve grafts provided early evidence that Schwann cells could support axonal regeneration of CNS neurons after SCI and ushered in the current era of neuroregeneration research for SCI. The use of intact peripheral nerve segments as bridges to facilitate axonal regeneration within the injured spinal cord has continued ${ }^{33,89}$ and has even been described in a case report of a patient with chronic paraplegia; after the repair, significant functional improvement was reported in the patient, who was previously confined to using a wheelchair but was able to ambulate independently using a walker after the procedure. ${ }^{34}$ Despite these impressive claims, it is difficult to draw strong conclusions from such a single case report.

The use of Schwann cells for transplantation has been the research focus of Bunge and coworkers ${ }^{165}$ at the Miami Project to Cure Paralysis. Using a contusive SCI model in the rat, these investigators have shown that Schwann cell transplantation can result in enhanced axonal regeneration and remyelination by transplanted cells, which was associated with a statistically significant, though very small, improvement in hindlimb function. Schwann cells are an attractive cellular candidate because they can be easily harvested from peripheral nerves (such as the sural nerve), expanded in vitro, then transplanted back into patients in an autologous fashion. Although the ability of Schwann cell transplants to enhance remyelination and support regenerative axon growth has been independently demonstrated by various groups, ${ }^{62,123,126,165}$ axons typically do not extend beyond the growth-permissive grafts to reinnervate the host spinal cord. Therefore, it is likely that the modest functional improvements observed in such experimental paradigms are attributable to remyelination of existing spared demyelinated axons, and not a result of axons making functionally meaningful synaptic connections with distal targets after regenerating through and out of a Schwann cell graft. This fact casts some significant doubt on the ultimate therapeutic utility of Schwann cell transplantation. However, the proven ability of Schwann cells to integrate into the injured cord parenchyma may make them well suited to serve as a delivery mechanism for other therapeutic molecules such as growth factors.

A novel source of Schwann cells has been identified with the recent discovery and isolation of so-called skinderived precursor cells, which are multipotent stem cells that have been derived from the dermis of adult mice ${ }^{154}$ and subsequently humans. ${ }^{155}$ Skin-derived precursor cells can be differentiated in vitro to produce myelinating Schwann cells, which have been shown to remyelinate axons and produce modest functional recovery following SCI in the rat. ${ }^{16}$ Although these cells offer the advantage of harvesting transplantable cells from a simple skin bi- opsy procedure, it is not yet known whether there will be a therapeutic advantage over Schwann cells derived from peripheral nerves.

\section{Olfactory Ensheathing Cells}

Olfactory ensheathing cells are a specialized glial cell originally described as olfactory nerve Schwann cells due to their morphological similarities. Olfactory ensheathing cells are unique in their ability to facilitate the passage of new axons from regenerating olfactory receptor neurons (which reside in the PNS within the olfactory mucosa) over long distances up to a mitral/tufted cell target neuron within the olfactory bulb glomeruli (CNS). This ability to seemingly escort axons across the "PNS to CNS barrier" has made OECs an extremely attractive potential transplantation substrate in SCIs, recognizing that despite the propensity of CNS axons to enter Schwann cell grafts (a PNS environment), it was difficult to get them to exit and reenter the hostile CNS environment to make functionally appropriate synapses.

Cotransplantation experiments with Schwann cells housed within guidance channels with OECs at either end revealed that the OECs could indeed facilitate enhanced regeneration of axons back into the spinal cord. ${ }^{133,134}$ This finding was followed by the reporting of axonal regeneration and functional recovery in a full transection SCI model after OEC transplantation. ${ }^{133}$ Interest in these cells has since grown immensely (for review see reference 132). Almost a decade of further work has curtailed the enthusiasm surrounding these cells to some extent, because it has become evident that some of the regeneration observed in OEC transplantation experiments may in fact be attributable to invading endogenous Schwann cells or by reportedly pure cultures of OECs becoming contaminated with Schwann cells, ${ }^{17,18}$ because the 2 cell types both express the majority of cell markers (such as p75) used to identify OECs. On the issue of myelination, under certain in vitro conditions, OECs (which never myelinate in vivo) have been reported to be capable of myelinating axons. ${ }^{43}$ However, the ability of the OEC to myelinate in vivo after transplantation into the injured spinal cord remains a subject of controversy, with the weight of evidence indicating that the OECs, in fact, do not form myelin. ${ }^{17}$ Whether they remyelinate in vivo or not, it appears that OECs are capable of creating an environment that is permissive for axonal growth, secreting factors that may be neuroprotective, modifying the glial scar by their interaction with astrocytes, and promoting angiogenesis. ${ }^{138}$ This potential has led to their use in numerous clinical trials outside North America (see Hawryluk et al. in this issue). Although the human trials reported to date have failed to demonstrate any significant benefits, ${ }^{45}$ there is hope that further optimization of culture and transplantation techniques and identification of appropriate time points for treatment postinjury will maximize the potential efficacy of OECs for SCI. Olfactory ensheathing cells are also a promising candidate for combinatorial cell-based strategies (OECs in combination with neural precursor cells) based on their apparent ability to integrate into the glial scar and enhance the growth permissiveness of the injured spinal cord. ${ }^{5}$ 


\section{Spinal cord injury pathophysiology and regenerative approaches}

\section{Neural Stem Cells and Glial Progenitors}

Neural stem cells are self-renewing, multipotent cells capable of producing all 3 neural lineages (neurons, astrocytes, and oligodendrocytes). Progenitor cells have a limited capacity for self-renewal and typically are unipotent, producing only 1 mature cell type of a given lineage. This distinction is an important one and use of the term "stem cell" has become increasingly confusing as it is often used in reference to any proliferating immature cell type in the CNS or other tissue. ${ }^{145}$ Although a detailed discussion of the characterization and definition of specific populations of stem and progenitor cells with therapeutic potential for SCI is well beyond the scope of this review, it is important to recognize that relevant biological differences may exist between seemingly interchangeable cell populations derived from embryonic or adult sources. For example, NSCs with the ability to survive and differentiate into mature, myelinating oligodendrocytes when transplanted into the demyelinated or injured rodent spinal cord have been derived from the embryonic CNS of mice ${ }^{67}$ and the postnatal and adult CNS of mice, ${ }^{49,80}$ rats, ${ }^{75,171}$ and humans. ${ }^{2,39}$ More importantly for developing therapies, NSCs and committed OPCs have been produced from both murine ${ }^{21,92}$ and human ESCs. ${ }^{82,116}$ The ideal source of myelinating cells for transplants is a matter that remains to be determined, although ESC-derived OPCs will likely emerge as the most clinically feasible source.

\section{Embryonic Stem Cell-Derived NPCs and OPCs}

Embryonic stem cells are pluripotent (that is, they can produce cell types from all 3 embryonic germ layers: mesoderm, endoderm, and ectoderm), self-renewing cells derived from the inner cell mass of blastocyst stage embryos. First derived from murine embryos, ${ }^{52,99}$ ESCs have subsequently been produced from human embryos. ${ }^{153}$ Due to their pluripotency in the undifferentiated state, ESCs require in vitro differentiation to commit them to a neural or glial fate prior to transplantation. Undifferentiated ESCs, or those that are not fully committed to the neural lineage, form teratomas following transplantation. ${ }^{135}$ Over the past decade, significant advances have been made in the ability to preferentially drive ESC differentiation into neural and specifically oligodendroglial lineages. First achieved using murine ESCs, the production of oligodendroglial lineage cells from ESCs followed by myelination has been demonstrated in vitro, ${ }^{92}$ and following transplantation into the demyelinated or injured spinal cord.21,92,102 After the original demonstration using murine ESCs, efforts began to produce human ESC-derived NPCs and OPCs. The production of a high-purity population of OPCs from human ESCs was first achieved by Hans Keirstead and coworkers. ${ }^{116}$ They subsequently demonstrated that these human ESC-derived OPCs resulted in remyelination and significantly improved locomotor function when transplanted 1 week after SCI in the rat. ${ }^{82}$ Currently, this approach is being considered to begin preliminary clinical trials (see Hawryluk et al. in this issue). ${ }^{158}$

The recent demonstration of the induction of an ESClike pluripotentiality in human adult somatic cells (skin fibroblasts) using the expression of specific transcription factors (Sox2, klf4, c-Myc, and Oct4) ${ }^{149}$ has opened up new possibilities for stem cell-based approaches for CNS injury and all other conditions as the potential for production of patient-specific cells of any type now exists. ${ }^{120,170}$ These genetically "reprogrammed" cells are termed iPSCs. Currently, the viral transfection techniques required to induce the pluripotent state in somatic cells would exclude clinical application. However, further development of this technology, such as the identification of small-molecule agents to mimic the actions of transcription factors, may one day make this a clinically viable cell source that would obviate the need for donor cell harvesting or immune suppression. Although this technology remains in its infancy, work to date has indicated that iPSCs behave similarly to bona fide ESCs in their response to differentiating signals and show no epigenetic abnormalities indicating that they are likely not associated with any risks greater than those of normal ESCs. ${ }^{98,113}$ The development of iPSCs is one of the most exciting developments within stem cell biology to date and continued investigation into their potential use as a source of NSCs or glial progenitors for use in SCI is highly warranted and the first data from their application in SCI models are eagerly anticipated.

\section{Adult-Derived NSCs}

The discovery of self-renewing NSCs in the adult mammalian CNS by Reynolds and Weiss ${ }^{136}$ and Weiss and colleagues ${ }^{160}$ revolutionized our view of the once thought static adult CNS. Following their discovery in the early 1990s, these cells were recognized as a potential means to promote the repair of the injured CNS. It has now been established that self-renewing NPCs can be isolated from the subventricular zone throughout the neuroaxis, ${ }^{152}$ and have been isolated in humans, ${ }^{39}$ including being successfully isolated endoscopically from the ventricular wall during routine neurosurgical procedures. ${ }^{161}$

The Fehlings laboratory has demonstrated the therapeutic potential of adult murine NPCs derived from the subventricular zone of the forebrain to remyelinate axons and improve locomotor recovery following contusive SCI in the rat. ${ }^{80}$ To more directly assess the correlation between NPC-mediated remyelination and improved axonal functional, the effect of NPC transplantation on the conduction properties of the spinal cord of the congenitally dysmyelinated shiverer mice was investigated. Shiverer mice lack central myelin due to a genetic deletion in the gene encoding myelin basic protein, a key structural component of CNS myelin. ${ }^{35}$ It was observed that NPCderived oligodendrocytes remyelinated axons in the shiverer spinal cord (Fig. 2), and these axons have improved axonal conduction measured electrophysiologically, and had normal-appearing nodes of Ranvier based on the establishment of the correct molecular organization of $\mathrm{K}$ and $\mathrm{Na}$ channels and the node-associated protein Caspr (contactin-associated protein). ${ }^{49}$

\section{Limitations of Remyelination Therapies for SCI}

Remyelination strategies are among the most promising SCI therapies under development and could prove to be the first embryonic stem cell-based therapies to under- 


\section{Spinal cord injury pathophysiology and regenerative approaches}
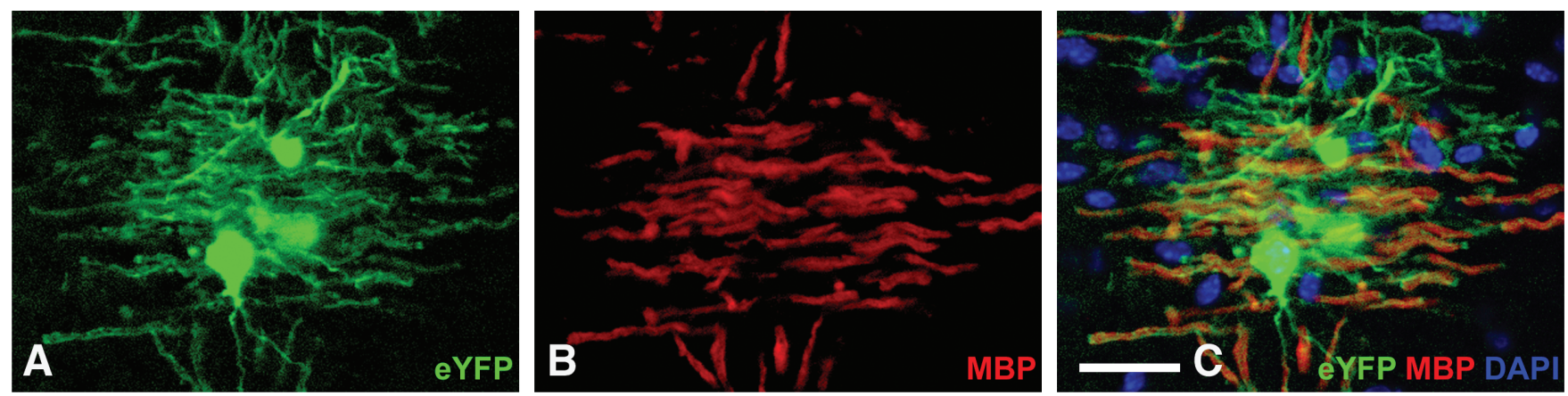

FIG. 2. Photomicrographs of myelination by transplanted neural precursor cells. Adult-derived NSCs differentiate into oligodendrocytes and myelinate when transplanted into the injured or demyelinated spinal cord. A: Image shows enhanced yellow fluorescent protein (eYFP) expressing adult-derived NPCs following transplantation into the dysmyelinated spinal cord of the shiverer mouse. Shiverer mice serve as a useful model of demyelination following SCl. B: The formation of myelin by NPCderived oligodendrocytes is confirmed by the expression of myelin basic protein (MBP; red), a myelin protein not expressed in the shiverer mouse due to a genetic mutation. C: Cell nuclei are counterstained with 4,6'-diamino-2-phenylindole-dihydrochloride (DAPI; blue). Bar $=20 \mu \mathrm{m}$.

go clinical trials in North America for any human condition. ${ }^{158}$ Although preclinical data in experimental SCI are highly encouraging, it must be understood that the potential functional improvement associated with any remyelinating therapy is limited by and a function of the number of spared, demyelinated axons present. As discussed earlier, the extent to which chronically demyelinated axons persist in human SCI is an unresolved issue. Therefore, within the highly heterogenous SCI population the efficacy of such treatments could potentially be highly variable among patients based on the characteristics of each specific lesion. Furthermore, the timing and methodology of such interventions remains to be optimized.

\section{Bone Marrow Stromal and Hematopoietic Stem Cells}

Adult mammalian bone marrow contains both HSCs and BMSCs, which are also known as MSCs. Both of these cell populations are unique, because they are ostensibly dedicated to the generation of hematopoietic cells such as erythrocytes and lymphocytes (HSCs) and mesenchymal cells such as osteocytes and chondrocytes (MSCs), and they both have been reported to have the ability to differentiate into neural lineage cells given the appropriate in vitro and in vivo conditions. ${ }^{124}$ The fact that they offer the potential for autologous transplantation, and that techniques for their harvesting from patients or donors are well established, make them appealing cell substrates for SCI repair.

The transplantation of HSCs into the injured spinal cord has been reported to promote functional recovery, but the mechanism behind this improvement (outside of merely surviving and differentiating) has not been well described and remains largely unknown. ${ }^{85,86}$ The transplantation of marrow stromal cells, on the other hand, has been shown to induce remyelination in the demyelinated spinal cord, although the myelin that was observed shared properties of both CNS and PNS myelin. ${ }^{3}$ The transplantation of MSCs into models of traumatic SCI has been inconsistently reported to result in some improved behavioral outcomes; however, in vivo the differentiation into neural lineage cells to support the remyelination is not particularly convincing, ${ }^{122}$ suggesting that other mechanisms may account for the enhanced myelination and functional improvements observed.

\section{Conclusions}

The structural and molecular pathology of SCI are formidable challenges to successful neural repair, challenges that we have yet to surpass, despite the best efforts of the scientific and clinical communities. A more comprehensive understanding of the complex biological processes, particularly in human cases of SCI, will be essential to our development of highly efficacious therapies. Efforts to induce regeneration and repair of the injured cord have led to translatable therapies directed at inhibiting myelin inhibitors, targeting intracellular messenger systems that mediate growth cone dynamics, and degrading the glial scar. Additionally, cell transplantation strategies have enormous momentum due to unparalleled scientific and public interest, although arguably many scientific and clinical aspects of a therapeutic transplantation paradigm still require resolution. The modest functional improvements obtained from the experimental therapies currently being developed clearly illustrates the need for combinatorial approaches that combine neuroprotective, neuroregenerative, and rehabilitative approaches in the hope of optimizing the recovery of individuals with traumatic SCI.

\section{Disclosure}

Michael Fehlings, M.D., Ph.D., has received financial support to conduct a clinical trial of Cethrin.

\section{References}

1. Ackery A, Robins S, Fehlings MG: Inhibition of Fas-mediated apoptosis through administration of soluble Fas receptor improves functional outcome and reduces posttraumatic axonal degeneration after acute spinal cord injury. J Neurotrauma 23:604-616, 2006

2. Akiyama Y, Honmou O, Kato T, et al: Transplantation of clonal neural precursor cells derived from adult human brain estab- 


\section{Spinal cord injury pathophysiology and regenerative approaches}

lishes functional peripheral myelin in the rat spinal cord. Exp Neurol 167:27-39, 2001

3. Akiyama Y, Radtke C, Kocsis JD: Remyelination of the rat spinal cord by transplantation of identified bone marrow stromal cells. J Neurosci 22:6623-6630, 2002

4. Anonymous: Spinal cord injury. Facts and figures at a glance. J Spinal Cord Med 28:379-380, 2005

5. Ao Q, Wang AJ, Chen GQ, et al: Combined transplantation of neural stem cells and olfactory ensheathing cells for the repair of spinal cord injuries. Med Hypotheses 69:1234-1237, 2007

6. Aoyama T, Hida K, Akino M, et al: Ultra-early MRI showing no abnormality in a fall victim presenting with tetraparesis. Spinal Cord 45:695-699, 2007

7. Austin JW, Fehlings MG: Molecular mechanisms of Fas-mediated cell death in oligodendrocytes. J Neurotrauma 25:411426, 2008

8. Bao F, Liu D: Peroxynitrite generated in the rat spinal cord induces apoptotic cell death and activates caspase-3. Neuroscience 116:59-70, 2003

9. Baptiste DC, Fehlings MG: Pharmacological approaches to repair the injured spinal cord. J Neurotrauma 23:318-334, 2006

10. Barbeau H, Rossignol S: Recovery of locomotion after chronic spinalization in the adult cat. Brain Res 412:84-95, 1987

11. Barritt AW, Davies M, Marchand F, et al: Chondroitinase ABC promotes sprouting of intact and injured spinal systems after spinal cord injury. J Neurosci 26:10856-10867, 2006

12. Beattie MS, Harrington AW, Lee R, et al: ProNGF induces p75-mediated death of oligodendrocytes following spinal cord injury. Neuron 36:375-386, 2002

13. Beattie MS, Hermann GE, Rogers RC, et al: Cell death in models of spinal cord injury. Prog Brain Res 137:37-47, 2002

14. Benson MD, Romero MI, Lush ME, et al: Ephrin-B3 is a myelin-based inhibitor of neurite outgrowth. Proc Natl Acad Sci U S A 102:10694-10699, 2005

15. Bethea JR, Nagashima H, Acosta MC, et al: Systemically administered interleukin-10 reduces tumor necrosis factor-alpha production and significantly improves functional recovery following traumatic spinal cord injury in rats. J Neurotrauma 16:851-863, 1999

16. Biernaskie J, Sparling JS, Liu J, et al: Skin-derived precursors generate myelinating Schwann cells that promote remyelination and functional recovery after contusion spinal cord injury. J Neurosci 27:9545-9559, 2007

17. Boyd JG, Doucette R, Kawaja MD: Defining the role of olfactory ensheathing cells in facilitating axon remyelination following damage to the spinal cord. FASEB J 19:694-703, 2005

18. Boyd JG, Skihar V, Kawaja M, et al: Olfactory ensheathing cells: historical perspective and therapeutic potential. Anat Rec B New Anat 271:49-60, 2003

19. Bradbury EJ, Moon LD, Popat RJ, et al: Chondroitinase ABC promotes functional recovery after spinal cord injury. Nature 416:636-640, 2002

20. Bregman BS, Kunkel-Bagden E, Schnell L, et al: Recovery from spinal cord injury mediated by antibodies to neurite growth inhibitors. Nature 378:498-501, 1995

21. Brustle O, Jones KN, Learish RD, et al: Embryonic stem cellderived glial precursors: a source of myelinating transplants. Science 285:754-756, 1999

22. Buffo A, Zagrebelsky M, Huber AB, et al: Application of neutralizing antibodies against NI-35/250 myelin-associated neurite growth inhibitory proteins to the adult rat cerebellum induces sprouting of uninjured Purkinje cell axons. J Neurosci 20:2275-2286, 2000

23. Bunge RP, Puckett WR, Becerra JL, et al: Observations on the pathology of human spinal cord injury. A review and classification of 22 new cases with details from a case of chronic cord compression with extensive focal demyelination. Adv Neurol 59:75-89, 1993

24. Caggiano AO, Zimber MP, Ganguly A, et al: Chondroitinase $\mathrm{ABCI}$ improves locomotion and bladder function following contusion injury of the rat spinal cord. J Neurotrauma 22:226-239, 2005

25. Cai D, Qiu J, Cao Z, et al: Neuronal cyclic AMP controls the developmental loss in ability of axons to regenerate. J Neurosci 21:4731-4739, 2001

26. Caroni P, Schwab ME: Antibody against myelin-associated inhibitor of neurite growth neutralizes nonpermissive substrate properties of CNS white matter. Neuron 1:85-96, 1988

27. Casha S, Yu WR, Fehlings MG: FAS deficiency reduces apoptosis, spares axons and improves function after spinal cord injury. Exp Neurol 196:390-400, 2005

28. Casha S, Yu WR, Fehlings MG: Oligodendroglial apoptosis occurs along degenerating axons and is associated with FAS and p75 expression following spinal cord injury in the rat. Neuroscience 103:203-218, 2001

29. Chaisuksunt V, Zhang Y, Anderson PN, et al: Axonal regeneration from CNS neurons in the cerebellum and brainstem of adult rats: correlation with the patterns of expression and distribution of messenger RNAs for L1, CHL1, c-jun and growthassociated protein-43. Neuroscience 100:87-108, 2000

30. Chau C, Barbeau H, Rossignol S: Early locomotor training with clonidine in spinal cats. J Neurophysiol 79:392-409, 1998

31. Chen MS, Huber AB, van der Haar ME, et al: Nogo-A is a myelin-associated neurite outgrowth inhibitor and an antigen for monoclonal antibody IN-1. Nature 403:434-439, 2000

32. Cheng B, Christakos S, Mattson MP: Tumor necrosis factors protect neurons against metabolic-excitotoxic insults and promote maintenance of calcium homeostasis. Neuron 12:139153, 1994

33. Cheng H, Cao Y, Olson L: Spinal cord repair in adult paraplegic rats: partial restoration of hind limb function. Science 273:510-513, 1996

34. Cheng H, Liao KK, Liao SF, et al: Spinal cord repair with acidic fibroblast growth factor as a treatment for a patient with chronic paraplegia. Spine 29:E284-E288, 2004

35. Chernoff GF: Shiverer: an autosomal recessive mutant mouse with myelin deficiency. J Hered 72:128, 1981

36. Chu GK, Yu W, Fehlings MG: The p75 neurotrophin receptor is essential for neuronal cell survival and improvement of functional recovery after spinal cord injury. Neuroscience 148:668-682, 2007

37. Coleman MP, Perry VH: Axon pathology in neurological disease: a neglected therapeutic target. Trends Neurosci 25:532-537, 2002

38. Crowe MJ, Bresnahan JC, Shuman SL, et al: Apoptosis and delayed degeneration after spinal cord injury in rats and monkeys. Nat Med 3:73-76, 1997

39. Cummings BJ, Uchida N, Tamaki SJ, et al: Human neural stem cells differentiate and promote locomotor recovery in spinal cord-injured mice. Proc Natl Acad Sci U S A 102:1406914074, 2005

40. David S, Aguayo AJ: Axonal elongation into peripheral nervous system "bridges" after central nervous system injury in adult rats. Science 214:931-933, 1981

41. David S, Aguayo AJ: Axonal regeneration after crush injury of rat central nervous system fibres innervating peripheral nerve grafts. J Neurocytol 14:1-12, 1985

42. Dergham P, Ellezam B, Essagian C, et al: Rho signaling pathway targeted to promote spinal cord repair. J Neurosci 22:6570-6577, 2002

43. Devon R, Doucette R: Olfactory ensheathing cells myelinate dorsal root ganglion neurites. Brain Res 589:175-179, 1992

44. Ditunno JF, Little JW, Tessler A, et al: Spinal shock revisited: a four-phase model. Spinal Cord 42:383-395, 2004 


\section{Spinal cord injury pathophysiology and regenerative approaches}

45. Dobkin BH, Curt A, Guest J: Cellular transplants in China: observational study from the largest human experiment in chronic spinal cord injury. Neurorehabil Neural Repair 20:5-13, 2006

46. Donnelly DJ, Popovich PG: Inflammation and its role in neuroprotection, axonal regeneration and functional recovery after spinal cord injury. Exp Neurol 209:378-388, 2007

47. Dubreuil CI, Winton MJ, McKerracher L: Rho activation patterns after spinal cord injury and the role of activated Rho in apoptosis in the central nervous system. J Cell Biol 162:233243, 2003

48. Edgerton VR, Kim SJ, Ichiyama RM, et al: Rehabilitative therapies after spinal cord injury. J Neurotrauma 23:560570, 2006

49. Eftekharpour E, Karimi-Abdolrezaee S, Wang J, et al: Myelination of congenitally dysmyelinated spinal cord axons by adult neural precursor cells results in formation of nodes of Ranvier and improved axonal conduction. J Neurosci 27:3416-3428, 2007

50. Ehlers MD: Deconstructing the axon: Wallerian degeneration and the ubiquitin-proteasome system. Trends Neurosci 27:3-6, 2004

51. Emery E, Aldana P, Bunge MB, et al: Apoptosis after traumatic human spinal cord injury. J Neurosurg 89:911-920, 1998

52. Evans MJ, Kaufman MH: Establishment in culture of pluripotential cells from mouse embryos. Nature 292:154-156, 1981

53. Fehlings MG: Summary statement: the use of methylprednisolone in acute spinal cord injury. Spine 26:S55, 2001

54. Fehlings MG, Tator $\mathrm{CH}$ : The relationships among the severity of spinal cord injury, residual neurological function, axon counts, and counts of retrogradely labeled neurons after experimental spinal cord injury. Exp Neurol 132:220-228, 1995

55. Filippi M, Rocca MA: Magnetization transfer magnetic resonance imaging of the brain, spinal cord, and optic nerve. Neurotherapeutics 4:401-413, 2007

56. Fleming JC, Norenberg MD, Ramsay DA, et al: The cellular inflammatory response in human spinal cords after injury. Brain 129:3249-3269, 2006

57. Fouad K, Schnell L, Bunge MB, et al: Combining Schwann cell bridges and olfactory-ensheathing glia grafts with chondroitinase promotes locomotor recovery after complete transection of the spinal cord. J Neurosci 25:1169-1178, 2005

58. Fournier AE, GrandPre T, Strittmatter SM: Identification of a receptor mediating Nogo-66 inhibition of axonal regeneration. Nature 409:341-346, 2001

59. Freund P, Schmidlin E, Wannier T, et al: Nogo-A-specific antibody treatment enhances sprouting and functional recovery after cervical lesion in adult primates. Nat Med 12:790-792, 2006

60. Freund P, Wannier T, Schmidlin E, et al: Anti-Nogo-A antibody treatment enhances sprouting of corticospinal axons rostral to a unilateral cervical spinal cord lesion in adult macaque monkey. J Comp Neurol 502:644-659, 2007

61. Garcia-Alias G, Lin R, Akrimi SF, et al: Therapeutic time window for the application of chondroitinase ABC after spinal cord injury. Exp Neurol 210:331-338, 2007

62. Golden KL, Pearse DD, Blits B, et al: Transduced Schwann cells promote axon growth and myelination after spinal cord injury. Exp Neurol 207:203-217, 2007

63. Grillner S: Locomotion in vertebrates: central mechanisms and reflex interaction. Physiol Rev 55:247-304, 1975

64. Grillner S: Neurobiological bases of rhythmic motor acts in vertebrates. Science 228:143-149, 1985

65. Grillner S: The motor infrastructure: from ion channels to neuronal networks. Nat Rev Neurosci 4:573-586, 2003

66. Hagg T, Oudega M: Degenerative and spontaneous regenerative processes after spinal cord injury. J Neurotrauma 23:264-280, 2006
67. Hammang JP, Archer DR, Duncan ID: Myelination following transplantation of EGF-responsive neural stem cells into a myelin-deficient environment. Exp Neurol 147:84-95, 1997

68. Hannila SS, Filbin MT: The role of cyclic AMP signaling in promoting axonal regeneration after spinal cord injury. Exp Neurol 209:321-332, 2008

69. Hata K, Fujitani M, Yasuda Y, et al: RGMa inhibition promotes axonal growth and recovery after spinal cord injury. $\mathbf{J}$ Cell Biol 173:47-58, 2006

70. Hayes KC, Potter PJ, Hsieh JT, et al: Pharmacokinetics and safety of multiple oral doses of sustained-release 4-aminopyridine (Fampridine-SR) in subjects with chronic, incomplete spinal cord injury. Arch Phys Med Rehabil 85:29-34, 2004

71. Herrmann JE, Imura T, Song B, et al: STAT3 is a critical regulator of astrogliosis and scar formation after spinal cord injury. J Neurosci 28:7231-7234, 2008

72. Hill CE, Beattie MS, Bresnahan JC: Degeneration and sprouting of identified descending supraspinal axons after contusive spinal cord injury in the rat. Exp Neurol 171:153-169, 2001

73. Hillard VH, Peng H, Zhang Y, et al: Tempol, a nitroxide antioxidant, improves locomotor and histological outcomes after spinal cord contusion in rats. J Neurotrauma 21:1405-1414, 2004

74. Ho CH, Wuermser LA, Priebe MM, et al: Spinal cord injury medicine. 1. Epidemiology and classification. Arch Phys Med Rehabil 88:S49-S54, 2007

75. Hofstetter CP, Holmstrom NA, Lilja JA, et al: Allodynia limits the usefulness of intraspinal neural stem cell grafts; directed differentiation improves outcome. Nat Neurosci 8:346-353, 2005

76. Houle JD, Tom VJ, Mayes D, et al: Combining an autologous peripheral nervous system "bridge" and matrix modification by chondroitinase allows robust, functional regeneration beyond a hemisection lesion of the adult rat spinal cord. J Neurosci 26:7405-7415, 2006

77. Ikegami T, Nakamura M, Yamane J, et al: Chondroitinase ABC combined with neural stem/progenitor cell transplantation enhances graft cell migration and outgrowth of growthassociated protein-43-positive fibers after rat spinal cord injury. Eur J Neurosci 22:3036-3046, 2005

78. Jenkins R, Tetzlaff W, Hunt SP: Differential expression of immediate early genes in rubrospinal neurons following axotomy in rat. Eur J Neurosci 5:203-209, 1993

79. Kakulas BA: Neuropathology: the foundation for new treatments in spinal cord injury. Spinal Cord 42:549-563, 2004

80. Karimi-Abdolrezaee S, Eftekharpour E, Wang J, et al: Delayed transplantation of adult neural precursor cells promotes remyelination and functional neurological recovery after spinal cord injury. J Neurosci 26:3377-3389, 2006

81. Keane RW, Kraydieh S, Lotocki G, et al: Apoptotic and antiapoptotic mechanisms following spinal cord injury. J Neuropathol Exp Neurol 60:422-429, 2001

82. Keirstead HS, Nistor G, Bernal G, et al: Human embryonic stem cell-derived oligodendrocyte progenitor cell transplants remyelinate and restore locomotion after spinal cord injury. J Neurosci 25:4694-4705, 2005

83. Kim BG, Dai HN, Lynskey JV, et al: Degradation of chondroitin sulfate proteoglycans potentiates transplant-mediated axonal remodeling and functional recovery after spinal cord injury in adult rats. J Comp Neurol 497:182-198, 2006

84. Kim GM, Xu J, Xu J, et al: Tumor necrosis factor receptor deletion reduces nuclear factor-kappaB activation, cellular inhibitor of apoptosis protein 2 expression, and functional recovery after traumatic spinal cord injury. J Neurosci 21:6617-6625, 2001

85. Koda M, Okada S, Nakayama T, et al: Hematopoietic stem cell and marrow stromal cell for spinal cord injury in mice. Neuroreport 16:1763-1767, 2005 


\section{Spinal cord injury pathophysiology and regenerative approaches}

86. Koshizuka S, Okada S, Okawa A, et al: Transplanted hematopoietic stem cells from bone marrow differentiate into neural lineage cells and promote functional recovery after spinal cord injury in mice. J Neuropathol Exp Neurol 63:64-72, 2004

87. Kwon BK, Tetzlaff W, Grauer JN, et al: Pathophysiology and pharmacologic treatment of acute spinal cord injury. Spine $\mathbf{J}$ 4:451-464, 2004

88. Lasiene J, Shupe L, Perlmutter S, et al: No evidence for chronic demyelination in spared axons after spinal cord injury in a mouse. J Neurosci 28:3887-3896, 2008

89. Lee YS, Hsiao I, Lin VW: Peripheral nerve grafts and aFGF restore partial hindlimb function in adult paraplegic rats. J Neurotrauma 19:1203-1216, 2002

90. Lehmann M, Fournier A, Selles-Navarro I, et al: Inactivation of Rho signaling pathway promotes CNS axon regeneration. J Neurosci 19:7537-7547, 1999

91. Lipton SA, Rosenberg PA: Excitatory amino acids as a final common pathway for neurologic disorders. N Engl J Med 330:613-622, 1994

92. Liu S, Qu Y, Stewart TJ, et al: Embryonic stem cells differentiate into oligodendrocytes and myelinate in culture and after spinal cord transplantation. Proc Natl Acad Sci U S A 97:6126-6131, 2000

93. Llado J, Haenggeli C, Maragakis NJ, et al: Neural stem cells protect against glutamate-induced excitotoxicity and promote survival of injured motor neurons through the secretion of neurotrophic factors. Mol Cell Neurosci 27:322-331, 2004

94. Lou J, Lenke LG, Ludwig FJ, et al: Apoptosis as a mechanism of neuronal cell death following acute experimental spinal cord injury. Spinal Cord 36:683-690, 1998

95. Low K, Culbertson M, Bradke F, et al: Netrin-1 is a novel myelinassociated inhibitor to axon growth. J Neurosci 28:1099-1108, 2008

96. Loy DN, Kim JH, Xie M, et al: Diffusion tensor imaging predicts hyperacute spinal cord injury severity. J Neurotrauma 24:979-990, 2007

97. Lu P, Jones LL, Snyder EY, et al: Neural stem cells constitutively secrete neurotrophic factors and promote extensive host axonal growth after spinal cord injury. Exp Neurol 181:115-129, 2003

98. Maherali N, Sridharan R, Xie W, et al: Directly reprogrammed fibroblasts show global epigenetic remodeling and widespread tissue contribution. Cell Stem Cell 1:55-70, 2007

99. Martin GR: Isolation of a pluripotent cell line from early mouse embryos cultured in medium conditioned by teratocarcinoma stem cells. Proc Natl Acad Sci U S A 78:7634-7638, 1981

100. McDonald JW, Becker D, Sadowsky CL, et al: Late recovery following spinal cord injury. Case report and review of the literature. J Neurosurg 97:252-265, 2002

101. McDonald JW, Belegu V: Demyelination and remyelination after spinal cord injury. J Neurotrauma 23:345-359, 2006

102. McDonald JW, Liu XZ, Qu Y, et al: Transplanted embryonic stem cells survive, differentiate and promote recovery in injured rat spinal cord. Nat Med 5:1410-1412, 1999

103. McDonald JW, Sadowsky C: Spinal-cord injury. Lancet 359:417-425, 2002

104. McKeon RJ, Schreiber RC, Rudge JS, et al: Reduction of neurite outgrowth in a model of glial scarring following CNS injury is correlated with the expression of inhibitory molecules on reactive astrocytes. J Neurosci 11:3398-3411, 1991

105. McKerracher L, David S, Jackson DL, et al: Identification of myelin-associated glycoprotein as a major myelin-derived inhibitor of neurite growth. Neuron 13:805-811, 1994

106. McKerracher L, Higuchi H: Targeting Rho to stimulate repair after spinal cord injury. J Neurotrauma 23:309-317, 2006

107. Mi S, Lee X, Shao Z, et al: LINGO-1 is a component of the Nogo-66 receptor/p75 signaling complex. Nat Neurosci 7:221-228, 2004

108. Monnier PP, Sierra A, Schwab JM, et al: The Rho/ROCK path- way mediates neurite growth-inhibitory activity associated with the chondroitin sulfate proteoglycans of the CNS glial scar. Mol Cell Neurosci 22:319-330, 2003

109. Moreau-Fauvarque C, Kumanogoh A, Camand E, et al: The transmembrane semaphorin Sema4D/CD100, an inhibitor of axonal growth, is expressed on oligodendrocytes and upregulated after CNS lesion. J Neurosci 23:9229-9239, 2003

110. Morgenstern DA, Asher RA, Fawcett JW: Chondroitin sulphate proteoglycans in the CNS injury response. Prog Brain Res 137:313-332, 2002

111. Mukhopadhyay G, Doherty P, Walsh FS, et al: A novel role for myelin-associated glycoprotein as an inhibitor of axonal regeneration. Neuron 13:757-767, 1994

112. Nagata S, Golstein P: The Fas death factor. Science 267:14491456,1995

113. Nakagawa M, Koyanagi M, Tanabe K, et al: Generation of induced pluripotent stem cells without Myc from mouse and human fibroblasts. Nat Biotechnol 26: 101-106, 2008

114. Nashmi R, Fehlings MG: Changes in axonal physiology and morphology after chronic compressive injury of the rat thoracic spinal cord. Neuroscience 104:235-251, 2001

115. Nashmi R, Fehlings MG: Mechanisms of axonal dysfunction after spinal cord injury: with an emphasis on the role of voltage-gated potassium channels. Brain Res Brain Res Rev 38:165-191, 2001

116. Nistor GI, Totoiu MO, Haque N, et al: Human embryonic stem cells differentiate into oligodendrocytes in high purity and myelinate after spinal cord transplantation. Glia 49:385-396, 2005

117. Noble LJ, Wrathall JR: Distribution and time course of protein extravasation in the rat spinal cord after contusive injury. Brain Res 482:57-66, 1989

118. Norenberg MD, Smith J, Marcillo A: The pathology of human spinal cord injury: defining the problems. J Neurotrauma 21:429-440, 2004

119. Park E, Velumian AA, Fehlings MG: The role of excitotoxicity in secondary mechanisms of spinal cord injury: a review with an emphasis on the implications for white matter degeneration. J Neurotrauma 21:754-774, 2004

120. Park IH, Zhao R, West JA, et al: Reprogramming of human somatic cells to pluripotency with defined factors. Nature 451:141-146, 2008

121. Park JB, Yiu G, Kaneko S, et al: A TNF receptor family member, TROY, is a coreceptor with Nogo receptor in mediating the inhibitory activity of myelin inhibitors. Neuron 45:345-351, 2005

122. Parr AM, Tator CH, Keating A: Bone marrow-derived mesenchymal stromal cells for the repair of central nervous system injury. Bone Marrow Transplant 40:609-619, 2007

123. Pearse DD, Sanchez AR, Pereira FC, et al: Transplantation of Schwann cells and/or olfactory ensheathing glia into the contused spinal cord: Survival, migration, axon association, and functional recovery. Glia 55:976-1000, 2007

124. Phinney DG, Prockop DJ: Concise review: mesenchymal stem/ multipotent stromal cells: the state of transdifferentiation and modes of tissue repair-current views. Stem Cells 25:28962902, 2007

125. Pineau I, Lacroix S: Proinflammatory cytokine synthesis in the injured mouse spinal cord: multiphasic expression pattern and identification of the cell types involved. J Comp Neurol 500:267-285, 2007

126. Pinzon A, Calancie B, Oudega M, et al: Conduction of impulses by axons regenerated in a Schwann cell graft in the transected adult rat thoracic spinal cord. J Neurosci Res 64:533-541, 2001

127. Popovich PG, Wei P, Stokes BT: Cellular inflammatory response after spinal cord injury in Sprague-Dawley and Lewis rats. J Comp Neurol 377:443-464, 1997

128. Priebe MM, Chiodo AE, Scelza WM, et al: Spinal cord 
injury medicine. 6. Economic and societal issues in spinal cord injury. Arch Phys Med Rehabil 88:S84-S88, 2007

129. Quencer RM, Bunge RP: The injured spinal cord: imaging, histopathologic clinical correlates, and basic science approaches to enhancing neural function after spinal cord injury. Spine 21:2064-2066, 1996

130. Radojicic M, Reier PJ, Steward O, et al: Septations in chronic spinal cord injury cavities contain axons. Exp Neurol 196:339341,2005

131. Ragnarsson KT: Functional electrical stimulation after spinal cord injury: current use, therapeutic effects and future directions. Spinal Cord 46:255-274, 2008

132. Raisman G, Li Y: Repair of neural pathways by olfactory ensheathing cells. Nat Rev Neurosci 8:312-319, 2007

133. Ramon-Cueto A, Cordero MI, Santos-Benito FF, et al: Functional recovery of paraplegic rats and motor axon regeneration in their spinal cords by olfactory ensheathing glia. Neuron 25:425-435, 2000

134. Ramon-Cueto A, Plant GW, Avila J, et al: Long-distance axonal regeneration in the transected adult rat spinal cord is promoted by olfactory ensheathing glia transplants. J Neurosci 18:38033815,1998

135. Reubinoff BE, Pera MF, Fong CY, et al: Embryonic stem cell lines from human blastocysts: somatic differentiation in vitro. Nat Biotechnol 18:399-404, 2000

136. Reynolds BA, Weiss S: Generation of neurons and astrocytes from isolated cells of the adult mammalian central nervous system. Science 255: 1707-1710, 1992

137. Richardson PM, McGuinness UM, Aguayo AJ: Axons from CNS neurons regenerate into PNS grafts. Nature 284:264265, 1980

138. Richter MW, Roskams AJ: Olfactory ensheathing cell transplantation following spinal cord injury: hype or hope? Exp Neurol 209:353-367, 2008

139. Sakamoto A, Ohnishi ST, Ohnishi T, et al: Relationship between free radical production and lipid peroxidation during ischemiareperfusion injury in the rat brain. Brain Res 554:186-192, 1991

140. Schanne FA, Kane AB, Young EE, et al: Calcium dependence of toxic cell death: a final common pathway. Science 206:700-702, 1979

141. Schnell L, Fearn S, Schwab ME, et al: Cytokine-induced acute inflammation in the brain and spinal cord. J Neuropathol Exp Neurol 58:245-254, 1999

142. Schnell L, Schwab ME: Axonal regeneration in the rat spinal cord produced by an antibody against myelin-associated neurite growth inhibitors. Nature 343:269-272, 1990

143. Schwab ME, Thoenen H: Dissociated neurons regenerate into sciatic but not optic nerve explants in culture irrespective of neurotrophic factors. J Neurosci 5:2415-2423, 1985

144. Scott GS, Cuzzocrea S, Genovese T, et al: Uric acid protects against secondary damage after spinal cord injury. Proc Natl Acad Sci U S A 102:3483-3488, 2005

145. Seaberg RM, van der Kooy D: Stem and progenitor cells: the premature desertion of rigorous definitions. Trends Neurosci 26:125-131, 2003

146. Sekhon LH, Fehlings MG: Epidemiology, demographics, and pathophysiology of acute spinal cord injury. Spine 26:S2S12, 2001

147. Stoodley MA: Pathophysiology of syringomyelia. J Neurosurg 92:1069-1073, 2000

148. Stys PK, Lipton SA: White matter NMDA receptors: an unexpected new therapeutic target? Trends Pharmacol Sci 28:561-566, 2007

149. Takahashi K, Yamanaka S: Induction of pluripotent stem cells from mouse embryonic and adult fibroblast cultures by defined factors. Cell 126:663-676, 2006

150. Tator $\mathrm{CH}$, Fehlings MG: Review of the secondary injury theory of acute spinal cord trauma with emphasis on vascular mechanisms. J Neurosurg 75:15-26, 1991

151. Tator CH, Koyanagi I: Vascular mechanisms in the pathophysiology of human spinal cord injury. J Neurosurg 86:483-492, 1997

152. Temple S, Alvarez-Buylla A: Stem cells in the adult mammalian central nervous system. Curr Opin Neurobiol 9:135-141, 1999

153. Thomson JA, Itskovitz-Eldor J, Shapiro SS, et al: Embryonic stem cell lines derived from human blastocysts. Science 282:1145-1147, 1998

154. Toma JG, Akhavan M, Fernandes KJ, et al: Isolation of multipotent adult stem cells from the dermis of mammalian skin. Nat Cell Biol 3:778-784, 2001

155. Toma JG, McKenzie IA, Bagli D, et al: Isolation and characterization of multipotent skin-derived precursors from human skin. Stem Cells 23:727-737, 2005

156. Totoiu MO, Keirstead HS: Spinal cord injury is accompanied by chronic progressive demyelination. J Comp Neurol 486:373383,2005

157. Totoiu MO, Nistor GI, Lane TE, et al: Remyelination, axonal sparing, and locomotor recovery following transplantation of glial-committed progenitor cells into the MHV model of multiple sclerosis. Exp Neurol 187:254-265, 2004

158. Vogel G: Cell biology. Ready or not? Human ES cells head toward the clinic. Science 308:1534-1538, 2005

159. Wang KC, Koprivica V, Kim JA, et al: Oligodendrocyte-myelin glycoprotein is a Nogo receptor ligand that inhibits neurite outgrowth. Nature 417:941-944, 2002

160. Weiss S, Dunne C, Hewson J, et al: Multipotent CNS stem cells are present in the adult mammalian spinal cord and ventricular neuroaxis. J Neurosci 16:7599-7609, 1996

161. Westerlund U, Svensson M, Moe MC, et al: Endoscopically harvested stem cells: a putative method in future autotransplantation. Neurosurgery 57:779-784, 2005

162. Wong ST, Henley JR, Kanning KC, et al: A p75(NTR) and Nogo receptor complex mediates repulsive signaling by myelin-associated glycoprotein. Nat Neurosci 5:1302-1308, 2002

163. Wrathall JR, Teng YD, Choiniere D: Amelioration of functional deficits from spinal cord trauma with systemically administered NBQX, an antagonist of non-N-methyl-D-aspartate receptors. Exp Neurol 137:119-126, 1996

164. Xiong Y, Rabchevsky AG, Hall ED: Role of peroxynitrite in secondary oxidative damage after spinal cord injury. J Neurochem 100:639-649, 2007

165. Xu XM, Guenard V, Kleitman N, et al: Axonal regeneration into Schwann cell-seeded guidance channels grafted into transected adult rat spinal cord. J Comp Neurol 351:145160, 1995

166. Yan P, Li Q, Kim GM, et al: Cellular localization of tumor necrosis factor-alpha following acute spinal cord injury in adult rats. J Neurotrauma 18:563-568, 2001

167. Yick LW, Cheung PT, So KF, et al: Axonal regeneration of Clarke's neurons beyond the spinal cord injury scar after treatment with chondroitinase ABC. Exp Neurol 182:160-168, 2003

168. Yiu G, He Z: Glial inhibition of CNS axon regeneration. Nat Rev Neurosci 7:617-627, 2006

169. Yong C, Arnold PM, Zoubine MN, et al: Apoptosis in cellular compartments of rat spinal cord after severe contusion injury. J Neurotrauma 15:459-472, 1998

170. Yu J, Vodyanik MA, Smuga-Otto K, et al: Induced pluripotent stem cell lines derived from human somatic cells. Science 318:1917-1920, 2007

171. Zhang SC, Ge B, Duncan ID: Adult brain retains the potential to generate oligodendroglial progenitors with extensive myelination capacity. Proc Natl Acad Sci U S A 96:4089-4094, 1999

172. Guest JD, Hiester ED, Bunge RP: Demyelination and 


\section{Spinal cord injury pathophysiology and regenerative approaches}

Schwann cell responses adjacent to injury epicenter cavities following chronic human spinal cord injury. Exp Neurol 192:384-393, 2005

173. Tetzlaff W, Kobayashi NR, Giehl KM, et al: Response of rubrospinal and corticospinal neurons to injury and neurotrophins. Prog Brain Res 103:271-286, 1994
Manuscript submitted July 15, 2008.

Accepted September 5, 2008.

Address correspondence to: Michael G. Fehlings, M.D., Ph.D., F.R.C.S.C., Toronto Western Hospital, McLaughlin Pavilion, 12th Floor, Room 407, 399 Bathurst Street, Toronto, Ontario, Canada, M5T 2S8. email: michael.fehlings@uhn.on.ca. 